\title{
A Study on 'Genomewide Selection' for Maize (Zea mays L.) Breeding in Japanese Public Sectors: Heritability of Maturity- and Yield-Related Traits in the Training Populations
}

\author{
Hiroyuki TAMAKI ${ }^{1 *}$, Hisashi SATO ${ }^{1,2}$, \\ Shohei MITSUHASHI ${ }^{1}$ and Tomohiro KIKAWADA ${ }^{1,2}$ \\ ${ }^{1}$ Forage Crop Research Division, NARO Institute of Livestock and Grassland Science (Nasushiobara, \\ Tochigi 329-2793, Japan) \\ ${ }^{2}$ Dairy Production Research Division, NARO Hokkaido Agricultural Research Center (Sapporo, Hok- \\ kaido 062-8555, Japan)
}

\begin{abstract}
The authors have considered introducing a molecular breeding technique called 'genomewide selection (GwS)' to effectively improve the yield of maize for whole-crop silage use. The GwS for this purpose requires training populations (TPs) where individual plants having been developed from three-way crosses are examined in their phenotypes as well as in molecular-marker genotypes. The purpose of this study was to evaluate the (broad-sense) heritability of maturity- and yield-related traits in such TPs, because a former simulation study by the authors showed that the heritability should exceed $25 \%$ for the success of the GwS. Five preliminary TPs were grown to estimate the heritability of silking date, ear dry weight and culm length from 2011 to 2013 on two planting density levels, the higher of which was for productivity testing and the lower for accurate individual phenotyping. The results indicated that heritability exceeded $25 \%$ in all cases, and that the higher planting density did not result in lower heritability. Accordingly, it was concluded that the maize GwS to improve yield is sufficiently feasible in terms of maintaining high heritability in the TPs, and that planting density for TPs should be that for productivity testing because it is known to have remarkable interaction on yield with genotypes.
\end{abstract}

Discipline: Plant breeding

Additional key words: best linear unbiased prediction (BLUP), culm length, inbred line, planting density, silking date

\section{Introduction}

There are concerns in Japan over the difficulties in ensuring long-term food supply, which has prompted the Japanese government to promote a policy to boost food self-sufficiency. A primary measure for this goal is to raise the feed self-sufficiency rate from 26 (in 2011) to $38 \%$ (MAFF 2011). The Japanese public sectors, to which the authors belong, are now expected to support this policy by breeding high-yield maize (Zea mays L.) varieties for whole-crop silage use highly adapted to Japanese climates.

As the cost of molecular genotyping has rapidly declined in recent years (e.g. Yan et al. 2010), it has become feasible for maize breeding teams in the Japanese public sectors to adopt certain molecular breeding techniques, where markers should be arranged over the whole genome (Tamaki et al. 2012). 'Genomewide selection (GwS)' is one such technique, the details and concept of which are explained in Meuwissen et al. (2001) and Bernardo \& Yu (2007). The focus of GwS is on accumulating favorable genes in many minor quantitative trait loci (QTLs) whereby the yield is deemed controlled (Yu \& Buckler 2006), and can be started from a biparental population, i.e. with molecular-marker information on a small number of inbred lines (hereinafter referred to as inbreds). Accordingly, the authors considered introducing $\mathrm{GwS}$ to effectively improve yield because maize breeding teams of the Japanese public sectors have accumulated less molecular-marker information on their materials.

The purpose of this study was to evaluate heritability (in the broad sense, hereafter the same) of maturity- and yield-related traits (on a whole-crop basis) in training populations (TPs) for GwS. For decades, the maize breeding teams of the Japanese public sectors have adopted programs

* Corresponding author: e-mail htamaki@affrc.go.jp

Received 10 March 2014; accepted 12 September 2014. 
where hybrid variety candidates have been developed from ' $\mathrm{D} \times \mathrm{F}$ ' (abbreviations for dent and flint genetic groups, respectively) combinations. Based on these breeding programs, it was assumed in the first computer simulation study by the authors (Tamaki et al. 2012) (1) that the breeding target was to develop a new dent inbred $\mathrm{D}_{\mathrm{N}}$, with high combining ability toward (i.e. eliciting a high yield in the hybrid) a specific flint tester inbred $\mathrm{F}_{\mathrm{T}}$, from a crossing of two existing inbreds $\mathrm{D}_{1}$ and $\mathrm{D}_{2}$, (2) that a TP was developed from a three-way cross ' $\left(D_{1} \times D_{2}\right) \times F_{T}$ ' to survey which of $\mathrm{D}_{1}$ or $\mathrm{D}_{2}$ would have higher combining ability toward $\mathrm{F}_{\mathrm{T}}$ on each genome region represented by each molecular marker, and (3) that eight individual plants of ' $\left(D_{1} \times D_{2}\right)$ ' in $F_{2}$ generation are selected from 1000; based solely on the genotypic information obtained in (2). The simulations have shown that GwS can be a powerful tool to effectively improve yield provided the following two conditions are fulfilled: i.e. (1) if molecular markers can be arranged over the whole genome at intervals of $20 \mathrm{cM}$ or shorter, and (2) if heritability in the TP is $25 \%$ or higher. The subsequent study (Tamaki et al. 2014) has investigated in the feasibility of the first condition by surveying single nucleotide polymorphisms (SNPs) in the inbreds of the Japanese public sectors. The results have been very positive; thousands of polymorphisms have been found over the whole genome. Accordingly, in this study, the focus of the authors' interest has shifted to the second condition, namely heritability in TPs. In maize breeding teams of the Japanese public sectors, heritability evaluation has only been performed from the analyses of variance (ANOVAs) for productivity testing where varieties and/or strains are arranged in a randomized complete block design, meaning that it has never been estimated on the individual phenotyping basis as required in GwS. Investigation and discussion will also be made in the adequate planting density of TPs for this purpose, and optimal linear unbiased prediction (BLUP) equation to adjust the yield fluctuation among rows in a TP.

\section{Materials and methods}

\section{Plant materials and investigated traits}

Table 1 shows the details of the preliminary training populations (PTPs, where the molecular genotyping of each individual plant remains pending). Entries in a PTP can be classified into two groups in terms of development; threeway and single crosses. The latter is mainly for heritability calculation (or, more strictly, to evaluate the size of nongenetic variance); details of which will be described below. All the inbreds were developed in the Japanese public sectors; National Agriculture and Food Research Organization (NARO) Hokkaido Agricultural Research Center (NARO/ HARC), Nagano Animal Industry Experiment Station (NAIES), NARO Kyushu Okinawa Agricultural Research
Center (NARO/KARC) and NARO Institute of Livestock and Grassland Science (NARO- ILGS) developed inbreds with names starting with "Ho", "Ki", "Mi" and "Na", respectively. The three PTPs containing "D", "11DL", "12DL" and "12DH", are for the assumed target to develop a new dent inbred, having high combining ability toward a flint inbred 'Na50', from two existing inbreds 'Mi29' and 'Na71'. These three inbreds are parents of registered commercial hybrid varieties (Ikegaya et al. 1999, Miki et al. 2011). The other two PTPs containing "F", "12FL" and "13FH" are for the assumed target to develop a new inbred, having high combining ability toward a dent inbred 'Mi88', from biparental crossings between a flint inbred ' $\mathrm{Na101}$ ' and one of flint or semi-dent inbreds, 'Ho95', 'Ki75', 'Na50', 'Mi106' or 'Mi111', because the hybrid from 'Mi88' and 'Na101' has a very high yield level, despite the difficulty in handling 'Na101'. (Semi-dent genetic group, to which 'Mi106' belongs, differs from either dent or flint, and has been found in previous studies, including Tamaki et al. (2014), to be as genetically distant to the dent as the flint. Accordingly, it was expected in the beginning of this study that 'Mi106' would have the potential to have equivalent combining ability toward dent 'Mi88' to the other four flint inbreds).

All PTPs were grown in a field of NARO-ILGS at Nasushiobara $\left(36^{\circ} 55^{\prime} \mathrm{N}, 139^{\circ} 56^{\prime} \mathrm{E}\right)$, to which $500 \mathrm{~kg} \mathrm{a}^{-1}$ of manure was applied in early spring as well as chemical fertilizer containing $1.0 \mathrm{~kg} \mathrm{a}^{-1} \mathrm{~N}+1.0 \mathrm{~kg} \mathrm{a}^{-1} \quad \mathrm{P}_{2} \mathrm{O}_{5}+$ $1.0 \mathrm{~kg} \mathrm{a}^{-1} \quad \mathrm{~K}_{2} \mathrm{O}$ before the seeding. Seeds of all PTPs were sowed in the second half of May, following practical maize cultivation around NARO-ILGS. Each individual plant was harvested 43-45, 39-40 and 39-41 days after silking in 2011, 2012 and 2013, respectively, following the usual harvesting rules for productivity testing in the maize breeding program of NARO-ILGS.

As shown in Table 1, PTPs were grown at two planting density levels, whose inter-row $\times$ intra-row spacing were $75 \times 30$ and $75 \times 20 \mathrm{~cm}$, corresponding to 444 and 667 plants $\mathrm{a}^{-1}$, respectively. In the maize breeding team of NAROILGS, where GwS operations are considered, the higher density is for productivity testing in line with the practical maize cultivation around NARO-ILGS, while the lower one is for individual selection (mainly for developing inbreds), where individual plants should be accurately phenotyped. Each PTP has a name ending in " $H$ " and " $L$ " to indicate higher and lower planting density, respectively.

The top of Table 3 shows the traits phenotyped in this study. Silking date and ear dry matter ratio are considered important indices for maturity, while culm length and basal stalk (60 cm-long) dry weight (only in "13FH") are candidate indices for whole stover yield, which is important for whole-crop silage use. Details of these two traits will be described below. 
Table 1. Details of preliminary training populations (PTPs) tested in this study

\begin{tabular}{|c|c|c|c|c|c|c|c|c|c|}
\hline \multirow{3}{*}{ Year } & \multirow{3}{*}{ Name } & \multicolumn{5}{|c|}{ Entries } & \multirow{3}{*}{$\begin{array}{c}\text { Planting } \\
\text { density } \\
\left(\text { plants } \mathrm{a}^{-1}\right)\end{array}$} & \multicolumn{2}{|c|}{ Date of } \\
\hline & & \multicolumn{3}{|c|}{ Three-way cross } & \multicolumn{2}{|c|}{ Single cross $(D \times F)^{1)}$} & & \multirow{2}{*}{ Seeding } & \multirow{2}{*}{$\begin{array}{l}\text { Harvest (days } \\
\text { after silking) }\end{array}$} \\
\hline & & Combination & Type $^{1)}$ & Number & Combination & Number & & & \\
\hline \multirow[t]{2}{*}{2011} & $11 \mathrm{DL}$ & $(\mathrm{Mi} 29 \times \mathrm{Na} 71) \times \mathrm{Na} 50$ & $(D \times D) \times F$ & 200 & $\mathrm{Mi} 29 \times \mathrm{Na} 50$ & & & & \\
\hline & & & & & $\mathrm{Na} 71 \times \mathrm{Na} 50$ & 32 each & 444 & Мay-18 & $43-45$ \\
\hline \multirow[t]{8}{*}{2012} & $12 \mathrm{DL}$ & " & " & 200 & " & 32 each & 444 & May-25 & $39-40$ \\
\hline & $12 \mathrm{DH}$ & " & " & 120 & " & 20 each & 667 & " & " \\
\hline & $12 \mathrm{FL}$ & Mi88×(Ho95×Na101) & & & Mi88×Ho95 & & & & \\
\hline & & Mi88×(Ki75×Na101) & & & Mi88×Ki75 & & & & \\
\hline & & $\mathrm{Mi} 88 \times(\mathrm{Na} 101 \times \mathrm{Na} 50)$ & $\mathrm{D} \times(\mathrm{F} \times \mathrm{F})$ & 30 each & $\mathrm{Mi} 88 \times \mathrm{Na} 50$ & & & & \\
\hline & & $\mathrm{Mi} 88 \times(\mathrm{Na} 101 \times \mathrm{Mi111})$ & & & $\mathrm{Mi} 88 \times \mathrm{Na} 101$ & 15 each & 444 & " & " \\
\hline & & $\operatorname{Mi} 88 \times\left(\mathrm{Na} 101 \times \mathrm{Mi1}^{2} 6^{2)}\right)$ & & & Mi88×Mi111 & & & & \\
\hline & & & & & Mi88 $\times \mathrm{Mi106}^{2)}$ & & & & \\
\hline \multirow[t]{3}{*}{2013} & $13 \mathrm{FH}$ & $\mathrm{Mi} 88 \times(\mathrm{Ki} 75 \times \mathrm{Na101})$ & & 202 & Mi88×Ki75 & & & & \\
\hline & & $\mathrm{Mi} 88 \times(\mathrm{Na} 101 \times \mathrm{Na} 50)$ & " & 207 & $\mathrm{Mi} 88 \times \mathrm{Na} 50$ & 27 each & 667 & May-17 & $39-41$ \\
\hline & & & & & $\mathrm{Mi} 88 \times \mathrm{Na} 101$ & & & & \\
\hline
\end{tabular}

1) $\mathrm{D}$ and $\mathrm{F}$ are abbreviations for dent and flint genetic groups, respectively.

2) 'Mi106' is defined as a flint genetic group member in this study, though it belongs to the semi-dent group, different from either dent or flint.

\section{Heritability estimation}

The heritability (in the broad sense) in a PTP, $\mathrm{H}_{\mathrm{B}}{ }^{2}$, where phenotyped were $N_{3}$ entry(ies) developed from threeway cross(es) and $N_{S}$ single cross entries, was estimated in this study from the following equation:

$$
\mathrm{H}_{\mathrm{B}}{ }^{2}=1-\frac{\frac{\sum_{L=1}^{N_{S}} v_{S}(L)}{N_{S}}}{\frac{\sum_{K=1}^{N_{3}} v_{3}(K)}{N_{3}}}
$$

where $v_{S}(L)$ and $v_{3}(K)$ are unbiased variances of the $L$-th $\left(1<L \leq N_{S}\right)$ single cross entry and of the $K$-th $\left(1 \leq K \leq N_{3}\right)$ entry developed from three-way cross, respectively. Equation (1) is based on the assumption of negligible genetic variance within a single cross entry.

\section{Assumption of non-genetic yield fluctuation among rows in a field test}

In the former simulation study (Tamaki et al. 2012), the authors assumed that rows in a TP (i.e. a test field) would have fluctuating environmental values on yield, which could be adjusted with the following best linear unbiased prediction (BLUP) equation

$y=X \beta+Z w+e$

where $y$ is an $N_{I} \times 1$ vector for the phenotypic data of the $N_{I}$ individual plants, $X$ is an $N_{I} \times N_{R}$ design matrix to express which individual plant is located on which row in the TP, $\beta$ is an $N_{R} \times 1$ unknown vector for environmental values of the $N_{R}$ rows, $Z$ is an $N_{I} \times N_{M}$ design matrix to express which individual plant has a molecular marker derived from which parent on which locus, $w$ is an $N_{M} \times 1$ unknown vector for breeding values of the $N_{M}$ markers, and $e$ is an $N_{I} \times 1$ vector for residual effects.

For the purpose of preliminary verification of these assumptions, the authors adopted the following equation modified from equation (2) in this study.

$y=X \beta+Z{ }^{\prime} w^{\prime}+e$

where $Z^{\prime}$ is an $N_{I} \times\left(N_{3}+N_{S}\right)$ design matrix to express which individual plant belongs to which entry in the PTP, and $w^{\prime}$ is an $\left(N_{3}+N_{S}\right) \times 1$ unknown vector for (average) values of $\left(N_{3}+N_{S}\right)$ entries (efforts have been made to establish each PTP for well-balanced material arrangement so that this BLUP matrix equation can be solved smoothly). From equation (3), we can obtain a vector for the best linear unbiased estimation (BLUE) values, or the estimated yield potential of each row, $\hat{\beta}$. In case $\hat{\beta}$ would effectively reflect the non-genetic yield fluctuation among the rows, this adjustment would remarkably raise the heritability. This adjustment was examined in terms of ear dry weight and basal stalk dry weight, but not culm length because its correlation to whole stover weight has been found to be relatively low (as described below). 


\section{Evaluation of candidate indices for whole stover yield}

As mentioned above, two traits were adopted in this study as candidate indices to predict whole stover yield, culm length and basal stalk dry weight. Here, they have been compared in terms of the accuracy of prediction, because neither has ever been evaluated as indices for this purpose. In 40 individual plants of " $13 \mathrm{FH}$ ", the whole stover of which was kept intact on harvest, the sampled contents included not only basal stalks but also other stover parts to compute their whole stover weight. The samples were then weighed after drying with a hot-air dryer (70 degrees centigrade) for more than 10 days.

\section{Results and discussion}

Table 2 shows the calculated heritability of ear and basal stalk dry weight with and without adjustment by the BLUP equation (3). The adjustment saw the heritability of the ear dry weight in "11DL" soar from 19.0 to $31.4 \%$, but decline somewhat in other cases where heritability was calculated as exceeding $40 \%$ without the adjustment. Based on these results, the authors decided to adopt this adjustment only for the ear dry weight of "11DL". Though more examples are required for convincing discussion, the authors currently estimate that the phenotypic fluctuation among the rows mainly reflects genetic and non-genetic factors in the cases of high $(>40 \%)$ and low $(<20 \%)$ heritability (without adjustment), respectively, and that the BLUP adjustment can only work well in the latter.

As shown in Table 3, the heritability ranged from 31.4 to $88.8 \%$, i.e. exceeded the threshold for the success of GwS which emerged in the former simulation study (Tamaki et al. 2012), 25\%, in all cases. It is interesting that higher planting density did not result in lower heritability, contrary to the assumptions the authors made beforehand that the higher density would trigger more severe intervention among individual plants, which would then lead to larger non-genetic variance and lower heritability. It has been concluded from these results that the planting density for TPs should be as high as that for productivity testing because it is well known to have remarkable interaction on yield with materials (genotypes) (e.g. Koinuma et al. 2004), and that the maize GwS to effectively improve yield remains sufficiently feasible in terms of maintaining high heritability in the TPs. Also considering numerous molecular-marker polymorphisms over the whole genome of the inbreds (Tamaki et al. 2014) as well as the recent rapid decline in the cost of molecular genotyping, maize GwS can be a powerful tool in the near future to accelerate yield breeding; not only in the Japanese public sector but also other breeding organizations having accumulated little information on molecular marker polymorphisms of their parental inbreds.

Fig. 1, showing the correlations of whole stover weight with its two candidate indices i.e. basal stalk dry weight (Fig. 1a) and culm length (Fig. 1b), clearly indicates that the former exceeds the latter. Though basal stalk dry weight has never been considered in maize breeding as an index for whole stover yield, these results suggest that it can be a powerful tool in the future, not only for GwS but also for productivity testing.

\section{Acknowledgements}

Here the authors express their deepest gratitude to $\mathrm{Mr}$. Masanori Muraki in the upland farming research division of NARO/KARC for his critical and heartwarming advice.

Table 2. Calculated heritability (\%) with and without BLUP ${ }^{1)}$ adjustment, and the ratio of population variance among the ridges

\begin{tabular}{lcccccc}
\hline \hline \multirow{2}{*}{$\begin{array}{c}\text { Trait } \\
\text { PTP }\end{array}$} & \multicolumn{5}{c}{ Ear dry weight } & BSDW \\
\cline { 2 - 5 } \cline { 3 - 5 } & 11DL & 12DL & 12DH & $12 \mathrm{FL}$ & $13 \mathrm{FH}$ & $13 \mathrm{FH}$ \\
\hline Calculated heritability & & & & & & \\
without BLUP & 19.0 & 42.2 & 53.5 & 48.1 & 55.4 & 49.2 \\
with BLUP & 31.4 & 39.4 & 47.3 & 45.2 & 50.0 & 47.4 \\
Adoption of & & & & & & \\
the adjustment & $\checkmark$ & - & - & - & - & - \\
\hline
\end{tabular}

1) Best linear unbiased prediction. See equation (3) in the text.

2) Basal stalk dry weight

3) Preliminary training population 


\section{References}

Bernardo, R. \& Yu, J. (2007) Prospects for genomewide selection for quantitative traits in maize. Crop Science, 47, 1082-1090.

Ikegaya, F. et al. (1999) Development and characteristics of new silage maize cultivar "Yumesodachi". Bulletin of the Kyushu agricultural experiment station, 35, 49-69 [In Japanese with English summary].

Koinuma, K. et al. (2004) Breeding of a silage maize cultivar, "Ohzora", with high yielding ability and lodging resistance. Research bulletin of national agricultural research center for Hokkaido region, 180, 1-17 [In Japanese with English summary].

Table 3. Field tests results and calculated heritability

\begin{tabular}{|c|c|c|c|c|c|c|c|c|c|c|c|c|}
\hline & \multicolumn{2}{|c|}{$\mathrm{PTP}^{1)}$ and entry / trait (unit) } & \multicolumn{2}{|c|}{$\begin{array}{l}\text { Silking date } \\
\text { (days after } \\
\text { June 30) }\end{array}$} & \multicolumn{2}{|c|}{$\begin{array}{l}\text { Ear dry matter } \\
\quad \text { ratio }(\%)\end{array}$} & \multicolumn{2}{|c|}{$\begin{array}{l}\text { Ear dry weight } \\
\left(\mathrm{g} \text { individual }{ }^{-1}\right)\end{array}$} & \multicolumn{2}{|c|}{$\begin{array}{l}\text { Culm length } \\
(\mathrm{cm})\end{array}$} & \multicolumn{2}{|c|}{$\begin{array}{c}\text { Basal stalk dry } \\
\text { weight } \\
\left(\text { g individual }^{-1}\right)\end{array}$} \\
\hline & & & Avg. ${ }^{2)}$ & $\mathrm{USD}^{3)}$ & Avg. ${ }^{2)}$ & $\mathrm{USD}^{3)}$ & Avg. ${ }^{2)}$ & $\mathrm{USD}^{3)}$ & Avg. ${ }^{2)}$ & $\mathrm{USD}^{3)}$ & Avg. ${ }^{2)}$ & $\mathrm{USD}^{3)}$ \\
\hline \multirow[t]{4}{*}{$11 \mathrm{DL}$} & Three-way & $(\mathrm{Mi} 29 \times \mathrm{Na} 71) \times \mathrm{Na} 50$ & 34.3 & 2.208 & 52.1 & 3.425 & 214 & 43.24 & 303 & 19.84 & & \\
\hline & \multirow[t]{2}{*}{ Single cross } & $\mathrm{Mi} 29 \times \mathrm{Na} 50$ & 36.1 & 1.370 & 53.0 & 2.039 & 222 & 36.02 & 302 & 12.85 & & \\
\hline & & $\mathrm{Na} 71 \times \mathrm{Na} 50$ & 33.9 & 2.014 & 52.1 & 2.875 & 210 & 35.62 & 302 & 13.23 & & \\
\hline & \multicolumn{2}{|c|}{ Heritability (\%) } & \multicolumn{2}{|c|}{39.2} & \multicolumn{2}{|c|}{47.0} & \multicolumn{2}{|c|}{31.4} & \multicolumn{2}{|c|}{56.8} & & \\
\hline \multirow[t]{4}{*}{$12 \mathrm{DL}$} & Three-way & $(\mathrm{Mi} 29 \times \mathrm{Na} 71) \times \mathrm{Na} 50$ & 34.9 & 1.606 & 50.0 & 3.659 & 224 & 32.48 & 315 & 16.93 & & \\
\hline & \multirow[t]{2}{*}{ Single cross } & $\mathrm{Mi} 29 \times \mathrm{Na} 50$ & 36.7 & 1.274 & 49.3 & 1.235 & 226 & 24.30 & 316 & 8.20 & & \\
\hline & & $\mathrm{Na} 71 \times \mathrm{Na} 50$ & 34.4 & 1.305 & 48.8 & 1.211 & 203 & 25.08 & 312 & 10.80 & & \\
\hline & \multicolumn{2}{|c|}{ Heritability (\%) } & \multicolumn{2}{|c|}{35.5} & \multicolumn{2}{|c|}{88.8} & \multicolumn{2}{|c|}{42.2} & \multicolumn{2}{|c|}{67.9} & & \\
\hline \multirow[t]{4}{*}{$12 \mathrm{DH}$} & Three-Way & $(\mathrm{Mi} 29 \times \mathrm{Na} 71) \times \mathrm{Na} 50$ & 35.1 & 1.821 & 47.9 & 2.973 & 171 & 41.99 & 319 & 16.00 & & \\
\hline & Single cross & $\mathrm{Mi} 29 \times \mathrm{Na} 50$ & 37.4 & 0.966 & 48.5 & 1.355 & 176 & 25.84 & 318 & 5.97 & & \\
\hline & & $\mathrm{Na} 71 \times \mathrm{Na} 50$ & 35.3 & 1.421 & 47.9 & 2.587 & 136 & 31.20 & 309 & 7.50 & & \\
\hline & \multicolumn{2}{|c|}{ Heritability (\%) } & \multicolumn{2}{|c|}{55.5} & \multicolumn{2}{|c|}{51.8} & \multicolumn{2}{|c|}{53.5} & \multicolumn{2}{|c|}{82.1} & & \\
\hline \multirow[t]{12}{*}{$12 \mathrm{FL}$} & Three-way & Mi88×(Ho95×Na101) & 32.6 & 2.230 & 52.5 & 2.029 & 172 & 18.45 & 303 & 21.40 & & \\
\hline & & Mi88×(Ki75×Na101) & 33.1 & 1.262 & 53.2 & 2.022 & 186 & 21.62 & 317 & 18.48 & & \\
\hline & & $\mathrm{Mi} 88 \times(\mathrm{Na} 101 \times \mathrm{Na} 50)$ & 35.6 & 1.502 & 51.9 & 1.927 & 191 & 30.99 & 319 & 15.32 & & \\
\hline & & Mi88×(Na101×Mi111) & 36.2 & 1.204 & 52.4 & 3.806 & 187 & 25.61 & 318 & 13.37 & & \\
\hline & & $\operatorname{Mi} 88 \times(\mathrm{Na} 101 \times \operatorname{Mi106})$ & 35.5 & 1.351 & 52.5 & 2.153 & 170 & 26.03 & 305 & 14.85 & & \\
\hline & Single cross & Mi88×Ho95 & 30.2 & 1.401 & 51.7 & 1.399 & 145 & 19.18 & 280 & 9.90 & & \\
\hline & & Mi88×Ki75 & 31.8 & 1.229 & 51.9 & 3.320 & 158 & 29.38 & 301 & 13.35 & & \\
\hline & & $\mathrm{Mi} 88 \times \mathrm{Na} 50$ & 35.6 & 0.996 & 52.6 & 1.137 & 204 & 10.50 & 308 & 9.68 & & \\
\hline & & Mi88×Na101 & 34.6 & 1.016 & 52.9 & 1.089 & 216 & 13.04 & 320 & 12.03 & & \\
\hline & & Mi88×Mi111 & 34.6 & 1.158 & 51.6 & 1.691 & 162 & 13.50 & 309 & 13.08 & & \\
\hline & & Mi88×Mi106 & 35.2 & 1.168 & 53.0 & 1.877 & 156 & 15.41 & 286 & 10.22 & & \\
\hline & Heritability ( $\%$ & & 43 & .5 & 41 & .4 & & .1 & 54 & 1 & & \\
\hline $13 \mathrm{FH}$ & Three-way & Mi88×(Ki75×Na101) & 23.5 & 2.103 & 51.0 & 1.894 & 145 & 31.32 & 317 & 18.65 & 30.7 & 7.440 \\
\hline & & $\mathrm{Mi} 88 \times(\mathrm{Na} 101 \times \mathrm{Na} 50)$ & 26.1 & 2.360 & 50.9 & 1.760 & 171 & 31.56 & 323 & 19.11 & 32.4 & 6.778 \\
\hline & Single cross & Mi88×Ki75 & 21.3 & 1.288 & 50.7 & 1.716 & 105 & 21.09 & 309 & 16.34 & 24.3 & 4.983 \\
\hline & & $\mathrm{Mi} 88 \times \mathrm{Na} 50$ & 25.9 & 0.933 & 50.4 & 0.989 & 176 & 17.64 & 322 & 13.31 & 29.3 & 3.145 \\
\hline & & $\mathrm{Mi} 88 \times \mathrm{Na101}$ & 25.0 & 1.214 & 51.2 & 0.863 & 193 & 23.81 & 329 & 11.94 & 36.5 & 6.520 \\
\hline & Heritability ( $\%$ & & 73 & .3 & 53 & & & .4 & 45 & 1 & & .2 \\
\hline
\end{tabular}

Italic letters indicate the results with the best linear unbiased prediction (BLUP) adjustment shown in the text.

1) Preliminary training population

2) Average

3) Unbiased standard deviation 
H. Tamaki et al.
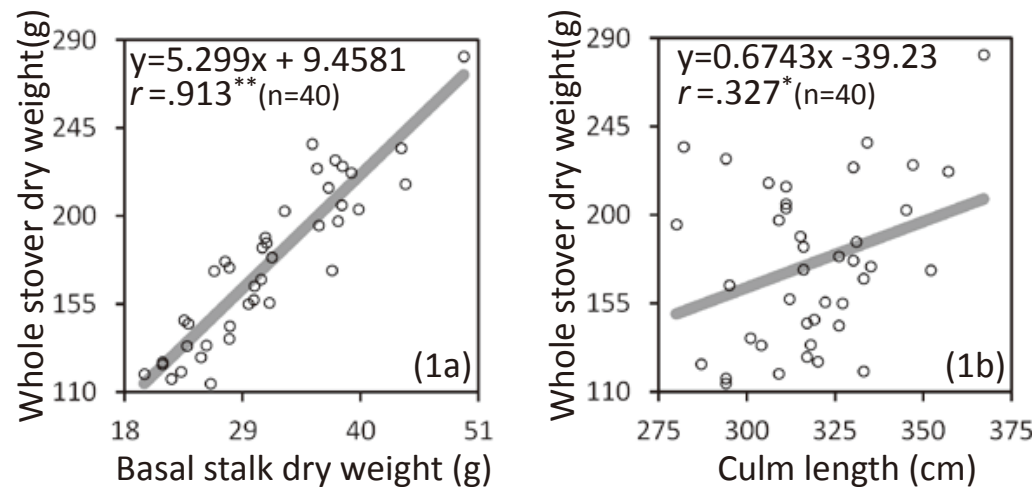

Fig. 1. The relationships of whole stover dry weight in the preliminary training population " $13 \mathrm{FH}$ " with basal stalk $(60 \mathrm{~cm}-\mathrm{long})$ dry weight (1a) and with culm length (1b)

MAFF (2011) FY2010 annual report on food, agriculture and rural areas in Japan -Summary. Ministry of Agriculture, Forestry and Fisheries of Japan, 1-60.

Meuwissen, T.H.E. et al. (2001) Prediction of total genetic value using genome-wide dense marker maps. Genetics, 157, 1819-1829.

Miki, K. (2011) Breeding of a medium maturing silage maize (Zea mays L.) cultivar "Takanehudou", with high yielding ability and lodging resistance. The Hokuriku crop science, 46, 9-13 [In Japanese].

Tamaki, H. et al. (2012) Preliminary study on 'genomewide selection' for maize (Zea mays L.) breeding in Japanese public sectors: Estimated selection response in the first selfing cycle of single-cross progeny. Grassland science, 58, 20-27.

Tamaki, H. et al. (2014) A study on 'genomewide selection' for maize (Zea mays L.) breeding in Japanese public sectors: single nucleotide polymorphisms observed among parental inbred lines. Bulletin of NARO institute of livestock and grassland science, 14, 1-11.

Yan, J. et al. (2010) High-throughput SNP genotyping with the GoldenGate assay in maize. Molecular breeding. 25, 445451.

Yu, J. \& Buckler, E. S. (2006) Genetic association mapping and genome organization of maize. Current opinion in biotechnology, 17, 155-160. 